\title{
Gümüş nano malzemelerin çevre dostu, hızlı sentezi ve biomedikal uygulamaları
}

\section{Eco- friendly, rapid synthesis of silver nanomaterials and their use for biomedical applications}

\section{Ayşe Baran}

Artuklu Üniversitesi, Lisansüstü Eğitimler Enstitüsü , Mardin, ayse.gorgec43@gmail.com

\begin{tabular}{|c|c|}
\hline MAKALE BİLGİLERİ & ÖZET \\
\hline Makale geçmişi: & \multirow{5}{*}{$\begin{array}{l}\text { Bu çalışmada, ceviz yaprakları kullanılarak hazırlanan özüt ile gümüş nano malzemeler çevre } \\
\text { dostu hılı ve basit bir şekilde sentezlendi. Elde edilen bu malzemelerin karakterizasyonu } \\
\text { UV-visiblespektrofotometre (UV-Vis.), Fourier dönüşümü kızılötesi spektroskopisi (FTIR), } \\
\text { X- Işınımı Kırınımı Difraktrometresi(XRD), Taramalı Elektron Mikroskobu (SEM), zeta } \\
\text { potansiyeli analiz verileri ile belirlendi. Gümüş nano malzemelerin } 454.01 \mathrm{~nm} \text { dalga boyunda } \\
\text { maksimum absorbans, } 23.66 \mathrm{~nm} \text { kristal nano boyut, küresel görünüm ve }-11.53 \mathrm{mV} \text { zeta } \\
\text { potansiyeline sahip oldukları belirlendi. Biomedikal ugulamalar için anti-mikrobiyal etkileri } \\
\text { patojen türler üzerinde incelendi. Bu türler üzerinde Minumum İnhibisyon Konsantrasyonları } \\
\text { (MİK) } 0.25-1.0 \mathrm{mg} / \mathrm{L} \text { olarak mikrodilusyon yöntemi ile belirlendi. }\end{array}$} \\
\hline Geliş: 15 Şubat 2021 & \\
\hline $\begin{array}{l}\text { Duzeltme: } 23 \text { Şubat } 2021 \\
\text { Kabul: } 23 \text { Şubat } 2021\end{array}$ & \\
\hline Anahtar kelimeler: & \\
\hline $\begin{array}{l}\text { XRD, anti-mikrobiyal, mikro } \\
\text { dilusyon, özüt }\end{array}$ & \\
\hline
\end{tabular}

Doi: $10.24012 /$ dumf. 880878

\begin{tabular}{l} 
ARTICLE INFO \\
\hline Articlehistory: \\
Received: 15 February 2021 \\
Revised: 23 February 2021 \\
Accepted: 23 February 2021 \\
\hline Keywords: \\
Bridge pier, local scour, clear \\
water scour, steady flow
\end{tabular}
water scour, steady flow

\begin{abstract}
In this study, silver nanomaterials were synthesized in an environmentally friendly, rapid and simple way with the extract prepared using walnut leaves. Characterization of these materials was determined by UV-visiblespectrophotometer (UV-Vis.), Fourier Transform Infrared Spectroscopy (FTIR), X-Ray Diffraction Diffractometer (XRD), Scanning Electron Microscopy (SEM), and Zeta potential analysis data. It was determined that silver nanomaterials have a maximum absorbance at $454.01 \mathrm{~nm}$ wavelength, $23.66 \mathrm{~nm}$ crystal nano size, spherical appearance and $-11.53 \mathrm{mV}$ zeta potential. For biomedical applications, antimicrobial effects were studied on pathogenic species. The Minimum Inhibition Concentrations (MIC) of these species were determined as $0.25-1.0 \mathrm{mg} / \mathrm{L}$ by microdilution method.
\end{abstract}

* Sorumlu yazar / Correspondence

Ayşe BARAN

$\triangle$ ayse.gorgec43@gmail.com 


\section{Giriş}

Nanoteknoloji, özellikle materyal biliminde aktif olması ile modern bilim dünyasında önemli bir yere sahiptir. Farklı boyut ve şekillere sahip nano materyallerin sentezlenmesi ve karakterizasyonu gibi konular çalışma alanını oluşturur [1], [2]. Nano materyallerin (nano partiküller) geniş yüzey alanına sahip olmaları, yüksek ısılara dayanıklı olmaları onları üstün yapan niteliklerden bazılarıdır. Bu özelikleri ile materyal bilimi, ilaç endüstrisi, elektronik gibi daha birçok alanda kullanımları mevcuttur [3], [4].

Metalik nanopartiküllerin kullanım alanlarının geniş olması ile kıymetli malzemelerdir. Gümüş $(\mathrm{Ag})$, altın (Au), demir (Fe), çinko (Zn) bunlardan bazılarıdır. Nanopartikülleri elde etmek için 1sıl işlemler, fotokimyasal ve kimyasal işlemler gibi farklı yöntemler kullanılmaktadır [5],[6],[7]. $\mathrm{Bu}$ yöntemlerin uygulama aşamaları yüksek maliyetler gerektirir. Aynı zamanda işlem sürecinde toksik kimyasalların kullanılmasında bu yöntemlerin dezavantajlı olduklarını göstermektedir. Son zamanlarda biyolojik yöntemler kullanilarak metalik nanopartiküllerin sentezlemesi uygulama kolaylığı çevre dostu oluşu ve maliyetin oldukça düşük olması ile ilgi görmektedir [8], [9].

Gümüş nanopartiküllerin çevre dostu yöntemler ile sentezinde birçok biyolojik kaynak kullanılmaktadır. Mantarlar [10], algler [11], bakteriler [12], bitkiler [13] bunlar arasında yer almaktadır. Bitkiler ile sentezinde daha fazla, hızlı ve hızlı nanopartiküller elde edilir. Ayrıca bu partiküllerin elde edilmesi daha kolay ve medikal uygulamalar için biyouyumlu olma özelliği gösterirler [3], [14], [15].

Bitkilerin yapısında bulunan alkoller, fenolik bileşikler, aromatik gruplar, aminler gibi fitokim yasallar sulu ortamda $\mathrm{Ag}^{+}$iyonunu indirgeyerek $\mathrm{Ag}^{\mathrm{O}}$ formunun oluşması ile nanopartikülleri meydana getirirler [16], [17].

Bu çalışmada Mardin bölgesinde yetişen Juglans regia $L$. (ceviz) ağacının yeşil yaprakları ile gümüş nanopartiküllerin (AgNP'leri) çevre dostu, basit, hızlı bir şekilde sentezlenmesi ve patojen mikroorganizmalar üzerinde üreme inhibisyonunun incelenmesi hedeflenmektedir.

\section{Materyal ve metot}

\section{Kullanılan kimyasallar ve cihazlar}

AgNP'leri sentezinde Sigma aldrich markalı $\mathrm{AgNO}_{3}$ (gümüş nitrat) tuzu kullanılarak $5 \mathrm{mM}$ (milimolar) çözelti hazırlandı. Mikro dilusyon yönteminde karşılaştırma yapmak için ticari olarak alınmıș vankomisin, kolistin ve flukonazol antibiyotikleri kullanıldı.

Perkin elmer one markalı UV-visible spektrofotometre (UV-Vis.) ve Fourier Dönüşümlü Kızılötesi spektroskopisi (FTIR), RadB-DMAX II bilgisayar kontrollü X-1şını Diftraktometresi (XRD), EVO 40 LEQ Taramalı Elektron Mikroskobu (SEM), RadBDMAX II bilgisayar kontrollü Enerji Dağılımlı X-1şınımı Kırınımı, Malvern marka Zeta potansiyeli cihazları kullanıldı. Partikülleri çöktürmek için de yüksek devirli OHAUS FC 5706 marka model cihaz ile santrifüj yapıldı.

\section{Sentez ve karakterizasyon}

Ceviz yaprakları yeşil formda ağustos ayı sonunda topland1. Önce musluk suyu ve ardından distile su ile bir kaç kez yıkandı oda koșullarında kurutuldu. Kuruyan yapraklardan $100 \mathrm{gr}$ alınd 1 ve $500 \mathrm{ml}$ distile su ile kaynatıldı. Oda koşullarında soğutulup süzgeç kağıdı ile süzme yapılarak sentez için kullanılmak üzere özüt elde edilmiş oldu.

$250 \mathrm{ml} 5 \mathrm{mM} \mathrm{AgNO} 3$ çözeltisi ile $500 \mathrm{ml}$ özüt karıștırılarak basit bir elle karıștırmanın ardından oda koşullarında sabit bir zemin üzerinde bırakıldı. Renk değişimi izlendi.

AgNP'lerin oluşum ve varlığını belirlemek için renk değişimine bağlı olarak belli aralıklar ile alınan numunelerle UV-vis. spektrofotometre cihazında dalga boyu taramaları yapılarak absorbanslar okundu. İndirgemeden sorumlu biyoaktif bileșenlere ait fonksiyonel grupları değerlendirmek amaciyla FTIR cihazı dataları incelendi. Sentez sonunda sulu ortamdan AgNP'leri çöktürmek için yüksek devirli santrifüj cihazı ile $9000 \mathrm{rpm}$ de santrifüj yapıldı. Elde edilen partikülller $75^{\circ} \mathrm{C}$ 'de kurutuldu. Kristal boyutlarını ve yapılarını değerlendirmek üzere XRD verileri incelendi. Morfolojik görünümleri ve element içerikleri SEM-EDX 
verileri ile belirlendi. AgNP'lerin yüzey yük dağılımı Zeta potansiyeli analiziyle belirlendi.

AgNP'lerin medikal uygulamalar için antimikrobiyal etkilerinin incelenmesi

AgNP'lerin anti-mikrobiyal etkileri patojen suşlar üzerinde Mikro Dilusyon yöntemi kullanılarak Minimum İnhibisyon Konsantrasyonu (MIK) ile belirlendi.

Patojen suşlardan Staphylococcus aureus ( $S$. aureus) ATCC 29213, Escherichia coli (E. coli) ATCC25922 ve Candida albicans (C. albicans) İnönü Üniversitesi Tıp Fakültesi Hastanesi Mikrobiyoloji Laboratuvarından, Bacillus subtilis (B. subtilis) ATCC 11774 ve Pseudomonas aeruginosa ( $P$. aeruginosa) suşları ise Mardin Artuklu Üniversitesi Mikrobiyoloji Araştırma Laboratuvarından tedarik edildi.

Katı formadaki besiyeri plaklarından üremiş olan patojen suşların her biri için Mc Farland

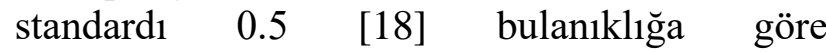
mikroorganizma süspansiyonları hazırlandı. 96'lık mikro plakala kuyucuklarına bakteriler için Muller Hinton sıvı besiyeri, maya için Roswell Park Memorial Institute (RPMI) siv1 besiyeri eklendi. İlk kuyucuğa $16 \mu \mathrm{g} / \mathrm{mL}^{-1}$ konsantrasyonda hazırlanan AgNP çözeltisi eklenip ilk kuyucuktan başlayarak bir seri mikro dilusyon yapıldı. Sonrasında her suş için Mc Farland 0.5 standart bulanıklık ile hazırlanan mikroorganizma süspansiyonundan kuyucuklara ekleme yapild 1 .

AgNP'lerin aktivitelerini karşılaştırmak için ticari olarak temin edilen gram pozitif suşlar $(S$. aureus ve $B$. subtilis) için vankomisin, gram negatif suşlar (E. coli ve $P$. aeruginosa) için kolistin antibiyotikleri ile maya $C$. albicans için de flukanozol antibiyotiklerine aynı şekilde mikro dilusyon uyguland. Mikro plakalar $37^{\circ} \mathrm{C}$ de 24 saat inkübasyona birakıldı. Ardından üreme kontrolu yapılarak üremenin başladığ kuyucuktan bir önceki kuyucuk MİK olarak belirlendi.

\section{Bulgular ve tartışma}

\section{Sentez ve karakterizasyon verileri}

Özüt ve $\mathrm{AgNO}_{3}$ çözeltisi karıştırıldıktan bir kaç dakika sonra sarıdan kahverengiye olan hızlı renk dönüşümü izlendi (Şekil 1.) [19]. AgNP'lerin oluşumu sırasinda indirgemeye bağlı olarak plazma yüzeyinde meydana gelen titreşimler (SPR) ile renk değişimi meydana gelmektedir [20]. Renk değişimine bağlı olarak UV-vis. spektroskopide yapılan okumalarda $454.01 \mathrm{~nm}$ dalga boyunda maksimum absorbans değerleri bulundu (Şekil 2). Yapılan benzer çalışmalarda $450 \mathrm{~nm}$ [21] ve $451 \mathrm{~nm}$ [22] maksimum dalga boyları ve sarıdan kahverengiye olan renk değişimi [23] AgNP'lerin oluşumu ve varlığı ile ilişkilendirilmiştir.

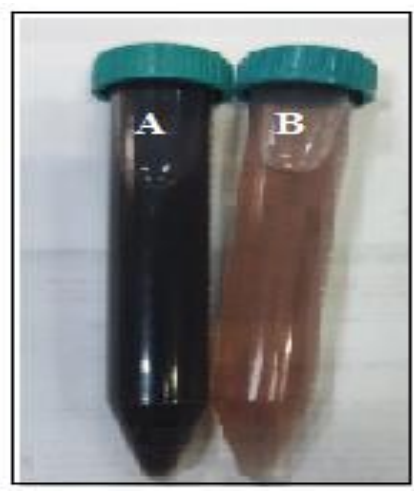

Şekil 1. A. Reaksiyondan sonra AgNP'lerin oluşumuna bağll meydana gelen renk değişimi B. Özüt görümü

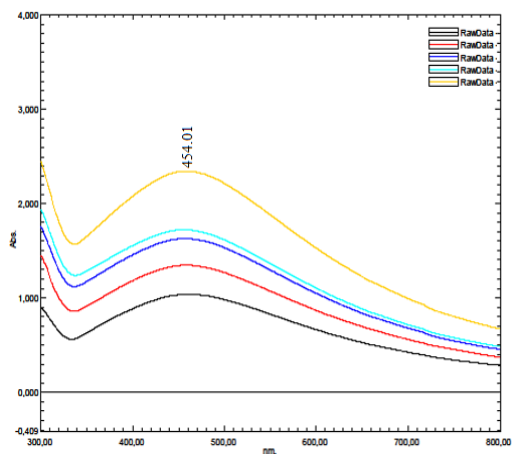

Şekil 2. AgNP'lerin oluşum ve varlı̆̆n gösteren $U V$-vis. Spektrofotometre verileri

FTIR datalarında indirgemeye katılan fonksiyonel gruplar incelendiğinde 3338.78$3336.66 \mathrm{~cm}^{-1}$ ve 2139.69-2107.04 $\mathrm{cm}^{-1}$ meydana gelen frekans kaymaları sirası ile $\mathrm{OH}($ hidroksil) grupların [24] ve $\mathrm{C} \equiv \mathrm{C}$ alkin 
gruplarin [25] indirgemeden sorumlu olabileceğini göstermektedir (Şekil 3.).
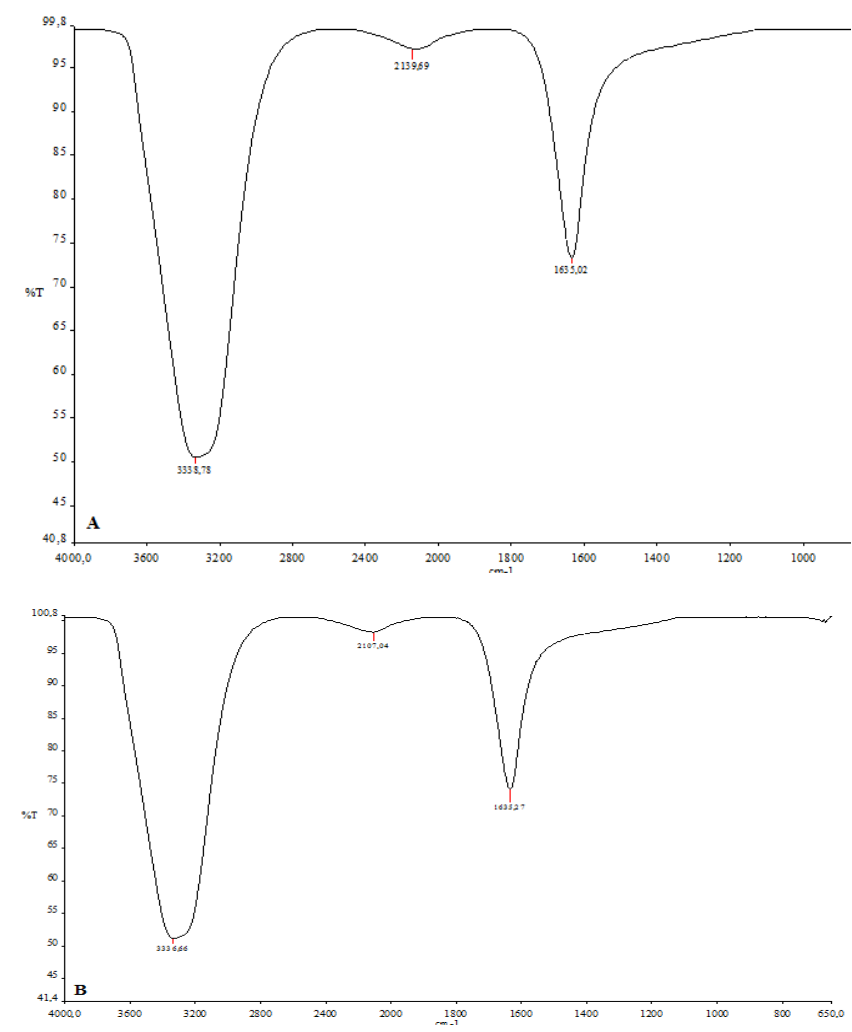

Şekil 3.Indirgemeden sorumlu fonksiyonal grupların değerlendirilmesi A.özüt, B.sentez sonrası reaksiyon sivı içeriğinine ait FTIR datalarl

AgNP'lerin kristal yapıları ve nano boyutları XRD ile $2 \theta$ da bulunan sonuçlara göre değerlendirildi. $111^{\circ}, 200^{\circ}, 220^{\circ}$ ve $311^{\circ}$ pikler gümüş nano kristallerin kubik yapıda olduklarını belirtir [26]. Bu piklere ait değerler siras1 ile 38.01, 44.32, 64.51 ve 77.20 olarak okunarak kristal nano boyut belirlemek için kullanıldı (Şekil 4.). Kristal nano boyutu DebyeScherrer eşitliği ile hesaplandı [27],[28].

$$
\mathrm{D}=\mathrm{K} \lambda /(\beta \cos \theta)
$$

Eşitlikte; $\mathrm{D}=$ partikül boyutu, $\mathrm{K}=$ sabit değeri (0.90), $\lambda=\mathrm{X}$-ray dalga boyu değeri (1.5418 $\AA$ ), $\beta=$ maksimum yüksekliğe sahip pikin FWHM değerinin yarısı, $\theta=$ yüksek pike ait Bragg açısını ifade etmektedir.

Elde edilen AgNP'lerin $23.66 \mathrm{~nm}$ kristal nano boyuta sahip oldukları hesapland1. Bazı çalışmalarda AgNP'lerin bu eşitlik kullanılarak $30.25 \mathrm{~nm}$ [8] ve 18.17 [25] nm kristal nano boyutta oldukları belirtilmiştir.

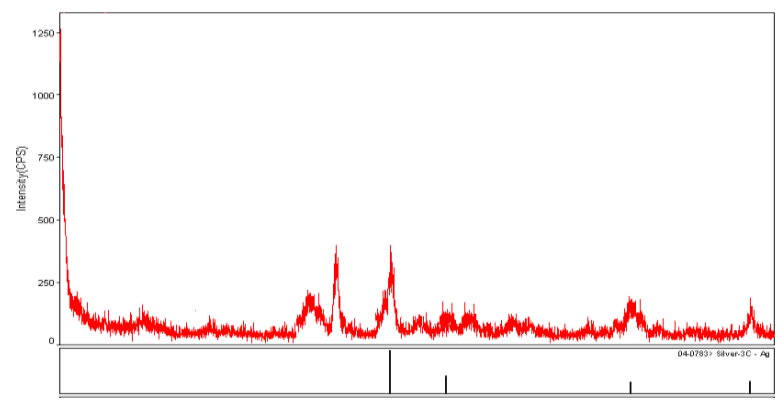

Şekil 4. AgNP'lerin XRD dataları

Şekil 5' de AgNP'lerin morfolojik yapıları ve element kompozisyonlarını belirlemek için SEM-EDX verileri incelendi. SEM grafisinde AgNP'lerin küresel görünümde [29] oldukları tespit edildi. EDX verilerinde ise gümüşe ait güçlü pikler AgNP'lerin varlığnı göstermektedir. Carbon ve oksijenden gelen zayıf pikler ise özütten gelen kirlilikten kaynaklanmaktadır [30].
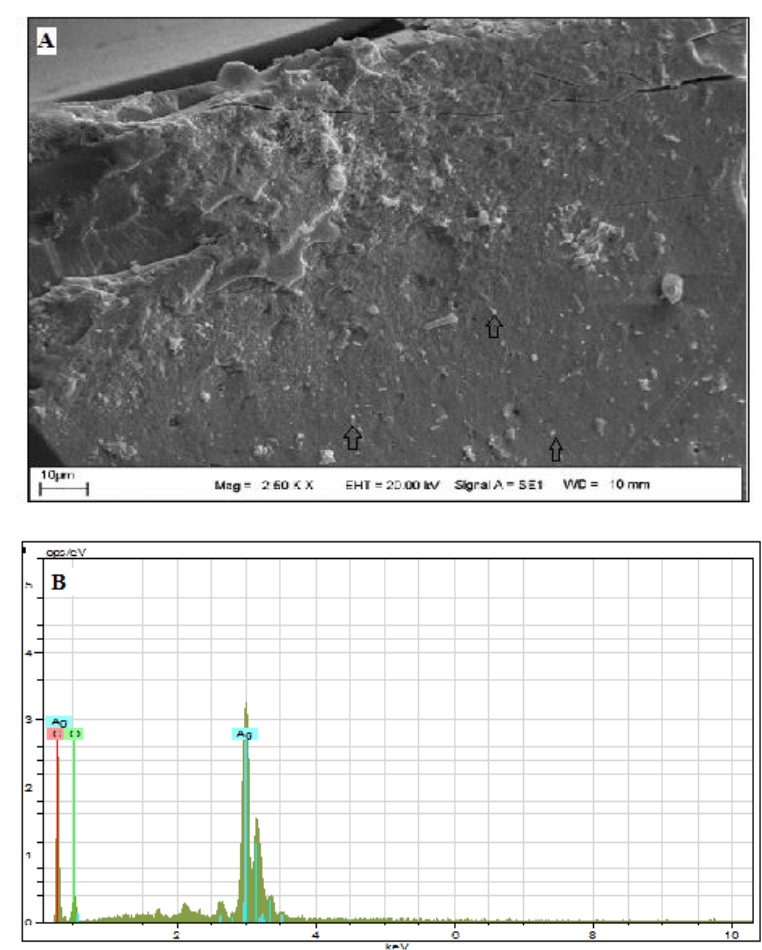

Şekil 5. AgNP'lerin SEM-EDX grafileri; $\boldsymbol{A}$. Morfolojik görümleri B. Element kompozisyonlart

Elde edilen AgNP'lerin yüzey yüklerini belirlemek için yapılan zeta potansiyeli analizi sonucu - $11.53 \mathrm{mV}$ olarak bulundu (Şekil 6).

Çevre dostu sentez çalışmalarında elde edilen AgNP'lerin zeta potansiyelleri -14 mV [24] ve $19 \mathrm{mV}$ [31] olarak tespit edilmiştir. 
AgNP'lerin yük bakımından negative dağılım göstermeleri önemlidir. Elde edilen AgNP'lerin sadece negatif yüke sahip olmaları kümelenmenin ve topaklanmanın olmadığını ve kararlı olduklarını belirtir [32].

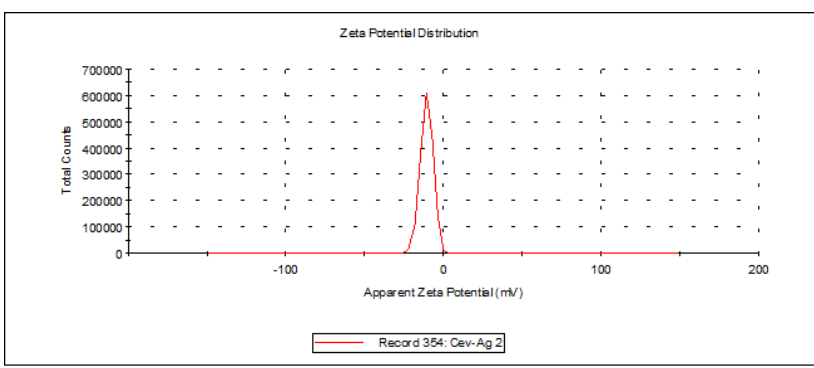

Şekil 6. AgNP'lerin yüzey yüklerini gösteren zeta potansiyeli analiz verileri

\section{AgNP'lerin anti-mikrobiyal incelenmesi}

Patojen suşlar üzerinde AgNP'lerin, antibiyotiklerin ve $5 \mathrm{mM}$ gümüş nitrat çözeltisinin anti-mikrobiyal etkileri mikro dilusyon yöntemi ile MIK belirlenerek karşılaştırıldı. Patojen suşlar üzerinde 0.25-1.0 $\mu \mathrm{g} / \mathrm{mL}$ konsantrasyonların etkili olduğu tespit edildi. $\mathrm{Bu}$ konsantrasyonlar antibiyotik ve gümüş nitrat çözeltisi ile kıyaslandığında daha düşük konsantrasyonda etkili olduklarını göstermektedir (Tablo 1 ve Şekil 7).

Tablo 1. Mikro dilusyon yöntemi ile elde edilen MIKK değerleri

\begin{tabular}{cccc}
\hline Patojen Suş & $\begin{array}{c}\text { AgNPs } \\
\mu \mathrm{g} / \mathrm{mL}\end{array}$ & $\begin{array}{c}\text { Silver } \\
\text { Nitrat } \\
\boldsymbol{\mu g} / \mathbf{m L}\end{array}$ & $\begin{array}{c}\text { Antibiyotik } \\
\boldsymbol{\mu g} / \mathbf{m L}\end{array}$ \\
\hline $\begin{array}{c}\text { S. aureus } \\
\text { ATCC 29213 }\end{array}$ & 0.25 & 2.65 & 2 \\
$\begin{array}{c}\text { B.subtilis } \\
\text { E. coli }\end{array}$ & 0.5 & 1.32 & 1 \\
ATCC25922 & 1.0 & 0.66 & 2 \\
P. aeruginosa & 1.0 & 1.32 & 4 \\
C. albicans & 0.25 & 0.66 & 2 \\
\hline
\end{tabular}

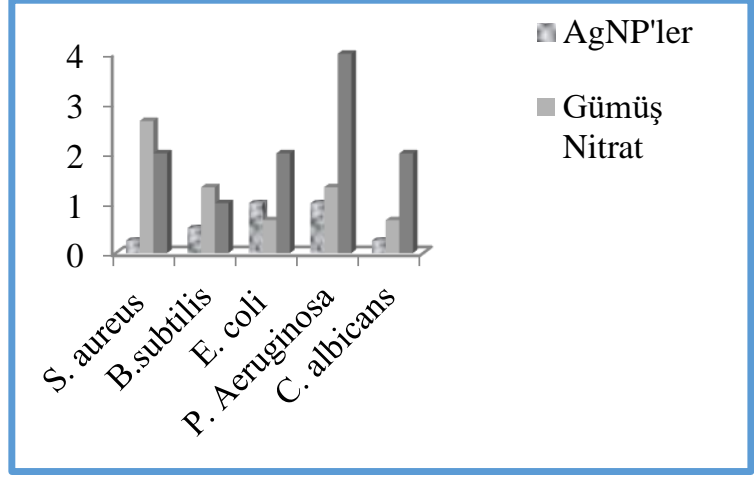

Şekil 7. Patojen suşlar üzerinde MiK uygulamalarının değerleri

Metalik gümüş iyonları kuru haldeyken inört özellik gösterirler. Sulu bir yapı içerisinde iyonize olurlar ve yüksek reaktivite gösterirler. İyonize olmuş gümüşler elektro statik çekim kuvveti ile mikroorganizmalar ile temas kurarlar [21], [33]. Reaktif oksijen türlerinin (ROS) artışına sebep olurlar. Artan ROS ile hücre duvarı, hücre membranı ve nükleus membranının yapısı bozulur [34]. Önemli biyomoleküllerin DNA, RNA gibi yapıların bu türlere karşı affinitesi bulunmaktadır. Dahası vital enzimlerin tiyol gruplarının bu türler ile güçlü bağ kurma özellikleri bulunmaktadır. $\mathrm{Bu}$ yapılarında faaliyetlerine etki ederek işlevlerini bozar ve hücre yıkımı ile ölümüne neden olurlar [35].

Yapılan benzer çalışmada yeşil çay özütü ile elde edilen AgNP'lerin $S$. aureus, E. coli ve $P$. aeruginosa bakterileri için sırası ile MIK değerleri $250 \mu \mathrm{g} / \mathrm{mL}, 15 \mu \mathrm{g} / \mathrm{mL}$ ve $30 \mu \mathrm{g} / \mathrm{mL}$ olarak belirtilmiştir [28]. Zea mays L. yaprak özütü ile elde edilen AgNP'lerin $S$. aureus üzerinde $0.33 \mu \mathrm{g} / \mathrm{mL}$ [36] ve bir diğer çalışmada ise $C$. albicans ve $B$. subtilis türleri için MİK 50 $\mu \mathrm{g} / \mathrm{mL}$ ve $25 \mu \mathrm{g} / \mathrm{mL}$ olarak raporlanmıştır [37].

\section{Sonuçlar}

Nano malzemelerin birçok kullanım alanı mevcuttur. $\mathrm{Bu}$ malzemelerin farklı elde etme metodları mevcuttur. Çevre dostu biyoaktif bileşiklerin kullanıldığı yöntemler büyük ilgi görmektedir. $\mathrm{Bu}$ yöntemin maliyeti düşük ve uygulama aşamaları kolay ve basittir. Özel şartlar gerektirmez ayrıca toksik kimysalların uygulama sürecinde olmayışı da avantaj sağlamaktadır. 
Juglans regia L. (ceviz) ağacının yeşil yaprakları ile elde edilen özüt ile AgNP'ler özütte bulunan fitokimysalların indirgeme kapasitesi ile hızlı, ekonomik ve basit bir şekilde yüksek enerji gereksinimi olmadan sentezlendi. Bu AgNP'ler UV-vis., FTIR, EDX, $\mathrm{XRD}, \mathrm{SEM}$ ve Zeta potansiyeli cihaz verileri ile karakterize edildi. AgNP'lerin küresel görünümde oldukları, $454.01 \mathrm{~nm}$ dalga boyunda maksimum absorbans ve $23.66 \mathrm{~nm}$ kristal nano boyut sahip oldukları belirlendi.

AgNP'lerin medikal uygulamalar için patojen türler üzerinde anti-mikrobiyal etkileri mikro dilusyon yöntemi kullanılarak MİK tespit edildi. Antibiyotiklerden daha düşük 0.25-1.0 $\mu \mathrm{g} / \mathrm{mL}$ konsantrasyonların etkili olduğu belirlendi.

Uygulama adımları geliştirilerek biyomedikal ve ilaç endüstrisi gibi alanlarda kullanımları anti-mikrobiyal ajan arayışına katkı sağlayabilir.

\section{Kaynaklar}

[1] Narayan, S., Dipak, S., (2015). Green synthesis of silver nanoparticles using fresh water green alga Pithophora oedogonia ( Mont .) Wittrock and evaluation of their antibacterial activity. Applied Nanoscience. 5, 703-709.

[2] Sudhakar, C., Selvam, K., Govarthanan, M., (2015). Acorus calamus rhizome extract mediated biosynthesis of silver nanoparticles and their bactericidal activity against human pathogens. Journal of Genetic Engineering and Biotechnology. 13 (2), 93-99.

[3] Ojo, O.A., Oyinloye, B.E., Ojo, A.B., Afolabi, O.B., Peters, O.A., Olaiya, O., Fadaka, A., Jonathan, j., Osunlana, O., (2017). Green Synthesis of Silver Nanoparticles ( AgNPs ) Using Talinum triangulare ( Jacq .) Willd . Leaf Extract and Monitoring Their Antimicrobial Activity. Journal of Bionanoscience. 11, 292-296.

[4] Baran, M.F., Keskin, C., Atalar, MN., Baran, A., (2021). Environmentally Friendly Rapid Synthesis of Gold
Nanoparticles from Artemisia absinthium Plant Extract and Application of Antimicrobial Activities. I $\check{g} d \imath$ Üniversitesi Fen Bilimleri Enstitüsü Dergisi. 11 (1), 365-375.

[5] Mohammadi, F., Yousefi, M., and Ghahremanzadeh, R., (2019). Green Synthesis , Characterization and Antimicrobial Activity of Silver Nanoparticles ( AgNps ) Using Leaves and Stems Extract of Some Plants. Advanced Journal of Chemistry-Section A. 2 (4), 266-275.

[6] Baran, M.F., Saydut, A., Umaz, A., (2019). Gümüş nanomalzeme sentezi ve antimikrobiyal uygulamaları Dicle Üniversitesi Mühendislik Dergisi. 10 (2), 689-695.

[7] Baran, M., (2019). Prunus avium kiraz yaprağ1 özütü ile gümüş nanopartikül ( AgNP ) sentezi ve antimikrobiyal etkisinin incelenmesi. Dicle Üniversitesi Mühendislik Dergisi. 10 (1), 221-227.

[8] Ali, Z.A., Yahya, R., Sekaran, S.D., Puteh, R., (2016). Green synthesis of silver nanoparticles using apple extract and its antibacterial properties. Advances in Materials Science and Engineering. 2016, 1-6.

[9] Baran, M. F., Saydut, A., (2019). Altın nanomalzeme sentezi ve karekterizasyonu. Dicle Üniversitesi Mühendislik Dergisi. 10 (3), 1033-1040.

[10] S, Majeed., Mohd, S. A., Gouri K. D., Mohammed, T.A., Anima, N., (2016). Biochemical synthesis of silver nanoprticles using filamentous fungi Penicillium decumbens (MTCC-2494) and its efficacy against A-549 lung cancer cell line. Chinese Journal of Natural Medicines. 14 (8), 615-620.

[11] Mousavi, S.A., Almasi, A., Navazeshkh, F., Falahi, F., (2019). Biosorption of lead from aqueous solutions by algae biomass: Optimization and modeling. Desalination and Water Treatment. 148, 229-237.

[12] Gopalu, K., Matheswaran J., Alexander, 
G., Juan, Antonio LT., Evgeny, K., D.K., (2016). Rapid Biosynthesis of AgNPs Using Soil Bacterium Azotobacter vinelandii With Promising Antioxidant and Antibacterial Activities for Biomedical Applications. The Journal of The Minerals, Metals \& Materials Society. 69, 1206-1212.

[13] Eren, A., Baran, M.F., (2019). Fistık ( Pistacia vera L . ) Yaprağından Gümüş Nanopartikül ( AgNP )' lerin Sentezi , Karakterizasyonu ve Antimikrobiyal Aktivitesinin İncelenmesi Synthesis , Characterization and Investigation of Antimicrobial Activity of Silver Nanoparticles ( AgNP ). 6 (2), 165-173.

[14] Ramkumar, V.S., Pugazhendhi, A., Gopalakrishnan, K., Sivagurunathan, P., Saratale, G.D., Dung, T.N.B., Kannapiran, E., (2017). Biofabrication and characterization of silver nanoparticles using aqueous extract of seaweed Enteromorpha compressa and its biomedical properties. Biotechnology Reports. 14, 1-7.

[15] Ahmed, M.J., Murtaza, G., Rashid, F., Iqbal, J., (2019). Eco-friendly green synthesis of silver nanoparticles and their potential applications as antioxidant and anticancer agents. Drug Development and Industrial Pharmacy I. 45 1682-1694.

[16] Patil, M.P., Singh, R.D., Koli, P.B., Patil, K.T., Jagdale, B.S., Tipare, A.R., Kim, G.D., (2018). Antibacterial potential of silver nanoparticles synthesized using Madhuca longifolia flower extract as a green resource. Microbial Pathogenesis. 121, 184-189.

[17] Song, J.Y., Kim, B.S., (2009). Rapid biological synthesis of silver nanoparticles using plant leaf extracts. Bioprocess and Biosystems Engineering. 32 (1), 79-84.

[18] Baran, M.F. (2019) Synthesis and Antimicrobial Applications of Silver Nanoparticles From artemisia absinthium plant. Biological and Chemical Research. 6, 96-103.
[19] Li, G., He, D., Qian, Y., Guan, B., Gao, S., Cui, Y., (2012). Fungus-Mediated Green Synthesis of Silver Nanoparticles Using Aspergillus terreus. International Journal of Molecular Sciences. 13, 466476.

[20] Kumar, V., Gundampati, R.K., Singh, D.K., Bano, D., Jagannadham, M. V., Hasan, S.H., (2016). Photoinduced green synthesis of silver nanoparticles with highly effective antibacterial and hydrogen peroxide sensing properties. Journal of Photochemistry and Photobiology B: Biology. 162, 374-385.

[21] Swamy, M.K., Akhtar, M.S., Mohanty, S.K., and Sinniah, U.R., (2015). Synthesis and characterization of silver nanoparticles using fruit extract of Momordica cymbalaria and assessment of their in vitro antimicrobial, antioxidant and cytotoxicity activities. Spectrochimica Acta - Part A: Molecular and Biomolecular Spectroscopy. 151, 939-944.

[22] Baran, M.F., (2019). Alıç Bitkisinin Yaprak Özütü Kullanılarak AgNP'erin Yeşil Sentezi ve Anti Mikrobiyal Aktivitelerinin Değerlendirilmesi. in: Gece Kitaplı̆̆ 1 , pp. 113-119.

[23] Pechyen, C., (2020). A flower shapegreen synthesis and characterization of silver nanoparticles ( AgNPs ). Integrative Medicine Research. 9 (5), 11003-11012.

[24] Remya, R.R., Rajasree, S.R.R., Aranganathan, L., Suman, T.Y., (2015). An investigation on cytotoxic effect of bioactive AgNPs synthesized using Cassia fistula flower extract on breast cancer cell MCF-7. Biotechnology Reports. 8 110-115.

[25] Baran, M.F., Koç, A., Uzan, S., (2018). Kenger (Gundelia tournefortii) Yaprağ İle Gümüş Nanopartikül(Agnp) Sentezi, Karakterizasyonu ve Antimikrobiyal Uygulamalar1. International Journal on Mathematic, Engineering and Natural Sciences. 5, 44-52. 
[26] Sampaio, S., Viana, J.C., (2018). Production of silver nanoparticles by green synthesis using artichoke (Cynara scolymus L.) aqueous extract and measurement of their electrical conductivity. Advances in Natural Sciences: Nanoscience and Nanotechnology. 9 (4), 1-10.

[27] Baran., M.F., (2019). Synthesis , Characterization And Investigation Of Antimicrobial Activity Of Silver Nanoparticles From Cydonia Oblonga Leaf. Applied Ecology and Environmental Research. 17 (2), 25832592.

[28] Rolim, W.R., Pelegrino, M.T., de Araújo Lima, B., Ferraz, L.S., Costa, F.N., Bernardes, J.S., Rodigues, T., Brocchi, M., Seabra, A. B., (2019). Green tea extract mediated biogenic synthesis of silver nanoparticles: Characterization, cytotoxicity evaluation and antibacterial activity. Applied Surface Science. 463, 66-74.

[29] Thomas, B., Vithiya, B.S.M., Prasad, T.A.A., Mohamed, S.B., Magdalane, C.M., Kaviyarasu, K., Maaza, M., (2018). Antioxidant and Photocatalytic Activity of Aqueous Leaf Extract Mediated Green Synthesis of Silver Nanoparticles Using Passiflora edulis f. flavicarpa . Journal of Nanoscience and Nanotechnology. 19 (5), 2640-2648.

[30] Arumai Selvan, D., Mahendiran, D., Senthil Kumar, R., Kalilur Rahiman, A., (2018). Garlic, green tea and turmeric extracts-mediated green synthesis of silver nanoparticles: Phytochemical, antioxidant and in vitro cytotoxicity studies. Journal of Photochemistry and Photobiology B: Biology. 180, 243-252.

[31] Oliveira, A.C. de J., Araújo, A.R. de, Quelemes, P.V., Nadvorny, D., SoaresSobrinho, J.L., Leite, José Roberto Sousa, A. S., Edson Cavalcanti, S., Durcilene A., (2019). Solvent-free production of phthalated cashew gum for green synthesis of antimicrobial silver nanoparticles. Carbohydrate Polymers. 213, 176-183.

[32] Patil, M.P., Singh, R.D., Koli, P.B., Patil, K.T., Jagdale, B.S., Tipare, A.R., Gun D., (2018). Antibacterial potential of silver nanoparticles synthesized using Madhuca longifolia flower extract as a green resource. Microbial Pathogenesis. 121, 184-189.

[33] Durán, N., Durán, M., Jesus, M.B. De, Seabra, A.B., Fávaro, W.J., Nakazato, G., (2015). Silver Nanoparticles: A New View on Mechanistic Aspects on Antimicrobial Activity. Nanomedicine: Nanotechnology, Biology, and Medicine. 12 (3), 789-799.

[34] Singh, P., Garg, A., Pandit, S., Mokkapati, V.R.S.S., (2018). Antimicrobial Effects of Biogenic Nanoparticles. Nanomaterials. 8 (12), 119.

[35] Gopinath, V., Priyadarshini, S., Loke, M.F., Arunkumar, J., Marsili, E., MubarakAli, D., Vadivelu, J., (2017). Biogenic synthesis, characterization of antibacterial silver nanoparticles and its cell cytotoxicity. Arabian Journal of Chemistry. 10 (8), 1107-1117.

[36] Eren, A., Baran, M.F, (2019). Green Synthesis , Characterization And Antımicrobial Activity Of Silver Nanoparticles ( Agnps ) From Maize ( Zea mays L .). Applied Ecology and Environmental Research. 17 (2), $4097-$ 4105.

[37] Emmanuel, R., Palanisamy, S., Chen, S., Chelladurai, K., Padmavathy, S., Saravanan, M., Fahad M.A, (2015). Antimicrobial ef fi cacy of green synthesized drug blended silver nanoparticles against dental caries and periodontal disease causing microorganisms. Materials Science \& Engineering C. 56 374-379. 